\title{
كشـاف الجملة
}

\section{من العـدد الأول إلى العـدد الثامـن والثلاثون}

العدد الأول

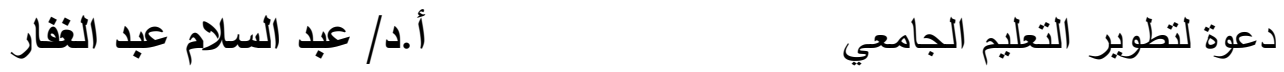
تحليل وتفسير لسلبيات الوضع الراهن في الحياة الجامعية في مصر .

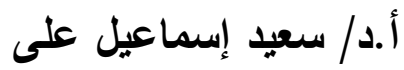

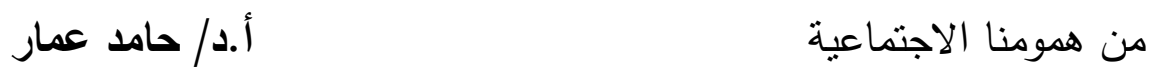

أ.د/ أحمد حسين اللقانى النمو العلمي والمهني للمعلم الجامعي اتجاهات جديدة "في تطوير التعليم الجامعي وإصلاحه" أ.د// عبد الفتاح أحمد حجاج

مؤشرات تقويمية لبرامج التعليم المفتوح في مصر أ.د/ محمود أبو زيد إبراهيم

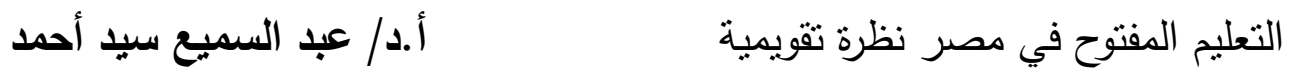
الأصول الاجتماعية والاقتصادية والثقافية للتعليم المفتوح في الجامعات أ.د/ محمد سيف الاين فهمي

الهيكل التتظيمي للجامعات وعلاقته باستقلالها المالي والإداري أ.د/ نادية عبد المنعم مصطلحات في التعليم الجامعي عرض كتاب " خمسة وجوه من هارفارد " تغير الثخصية خلال السنوات الدراسية الجامعية

أ.د// أحمد حسين اللقانى العدد الثاني التربية البيئية في برامج إعداد المعلمين في الجامعات أ.د/ محمد صابر سليم أ.د/ أد عبد الغنى عبود الجامعة نظام قيمي 
اتجاهات كليات التربية بالدقهلية نحو حماية البيئة من التلوث (دراسة ميدانية)

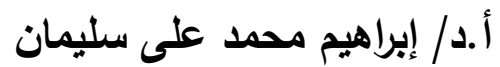

القدرات العقلية اللازمة لعملية التشكيل على المانيكان وعلاقتها بمستوى أداء الطلاب.

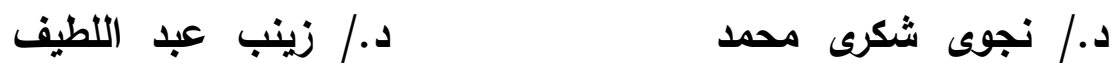

دراسة العلاقة بين تدريس المعلومات وتحصيلها خلال بعض أساليب التدريس الجامعي لدى طلاب العلوم الاجتماعية بكلية التربية بالمدينة المنورة د./ عبد المنعم بن صفى الجزار

دراسة العلاقة بين تدريس المعلومات وتحصيلها خلال بعض أساليب التدريس الجامعي لدى طلاب العلوم الاجتماعية بكلية التربية بالمدينة المنورة أ.د// يسرى عفيفى عفيفى

تقويم الأوراق الامتحانية بكلية التربية جامعة السلطان قابوس د./ عبد اللطيف بن صفى الجزار

دراسة مقارنة لأثز توزيع وتتابع الجانب العلمى مع الجانب النظرى على الهيكل النهائى فى تصميم مقرر تكنولوجيا التعليم فى برامج إعداد المعلمين بالجامعة

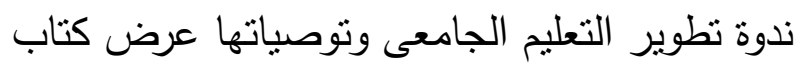

Teaching Large Classes in Higher Education: How to Maintain Quilty With Reducer Resources. Kogan Pagel, land, 1992.

أ.د/ عبد السميع سيد أحمد عرض رسالة دكتوراه: دراسة مقارنة للخبرات العربية والأجنبية باللغة القومية بالجامعات وإمكانية الاستفادة منها فى جمهورية مصر العربية الباحث/ أحمد فريد عباس عبد العال

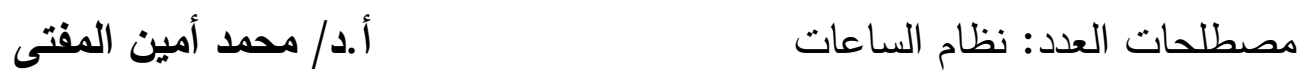


أ. أد/ حسن شحاته

كلمة الافتناح

أ.د/ حسين كامل بهاء الدين "وزيـر التعليم"

أبحاث ودراسات قضية أمن قومي

نظام الساعات المعتمدة بكلية التربية، سلطنة عمان -قطر د./ بيومى محمد ضحاوى التوسع في الفرص التعليمية وجودة التعليم الجامعي د./ سعاد بسيونى عبد الغتى

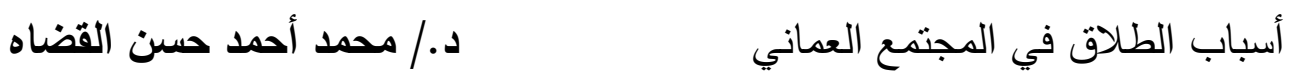
ملف العدد

التقويم الجامعي خبرة جامعة حلوان في مجال تقويم الجامعات - جامعة حلوان د./ فتحية حسنى محمد

\section{التقوبم الذاتي: مدخل جديد لتطويره الممارسات التعليمية أبحاث باللغة الإنجليزية}

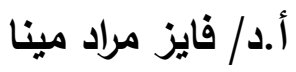
الجامعة التقليدية وتحولها: حالة العالم العربي ملخصات رسائل جامعية دور جامعة قناة السويس في خدمة المجتمع المحلى د./. زينب عبد النبى أحمد

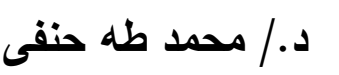
نظم تقويم الطلاب بكليات التربية في مصر وإنجلترا

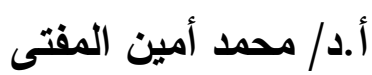
موسوعة التعليم الجامعي جامعة القس المفتوحة 


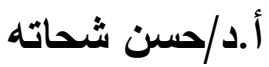

المسئولية الاجتماعية لدى طلاب شعبة التاريخ بكلية التنربية د / إمام مختار حيدة

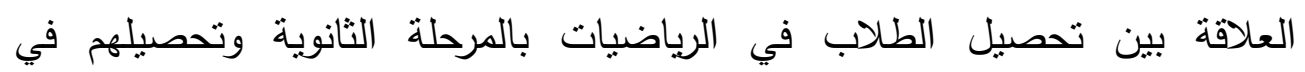
الرياضيات بالجامعات د./شكرى سيد أحمد برنامج مقترح لتنمية بعض مهارات التواصل البصرية لاى الطالبات المعلمات

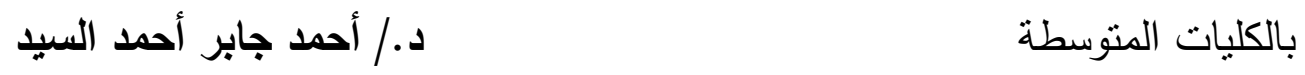
موقف بن الأثثر من الاستشهاد بالثعر في كتابه الكامل في التاريخ د. د. طاهر راغب حسين

برنامج الإعداد الأكاديمي لمعلمة العلوم بكلية البنات - شعبة التعليم الابتدائي - دلئ راعبين

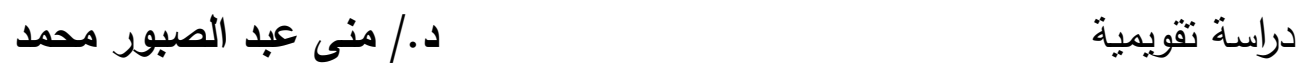

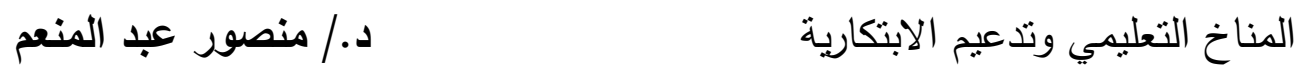
أخطاء الإنثاء لاى طلاب المعلمين من خلال نظرية إنقان التعلم

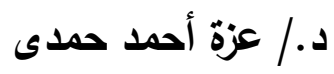

\section{ملخصات رسائل جامعية}

بناء وتتمية المجموعات في المكتبة المركزية بجامعة عين شمس د. دم/ محمد يوسف محمد مراد

طلاق التعسف في الفقه الإسلامي - دراسة مقارنة د/ محمد أحمد حسن القضاه 
أ.د// على السيد الشخيبى

اتجاهات حديثة فى تمويل التعليم الجامعى أدد/ الهلالى الشربينى الهلالى تحسين الفعالية التتظيمية للجامعات المصرية فى ضوء مدخل التعليم التتظيمى د/ أسامة محمود قرنى د/ أحمد محمد غانم " التعليم المتتاوب كصيغة تربوية لتعليم الكبار ، فلسفته وأهدافه ومتطلبات تطبيقه فى

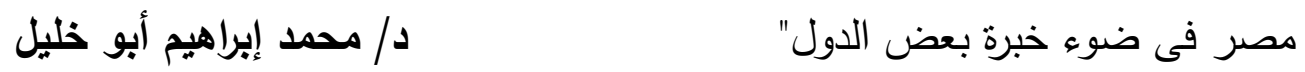
" تعليم المرأة السعودية ومدى إسهامه فى التتمية الاقتصادية والاجتماعية فى عهد

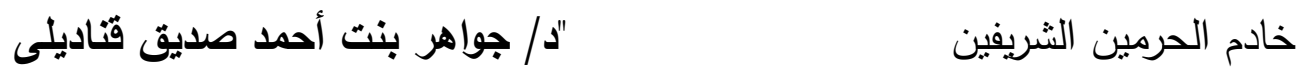
الحقيبة التدريبية لتطوير كفايات رؤساء الأقسام بالجامعات العربية مركز تطوير التعليم الجامعى

ملخصات رسائل علمية اتجاهات النخبة العربية "الفلسطينية" نحو تطوير جامعة القدس المفتوحة فى ضوء

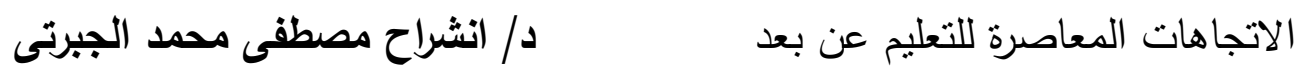
بعض متطلبات تطوير الدراسات العليا فى كليات التربية بمصر فى ضوء بعض الت

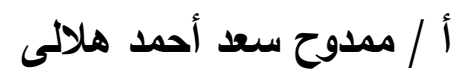
الاتجاهات المعاصرة تصور مقترح لتطبيق نظام التعليم المفتوح بجامعة الأزهر فى ضوء رسالة الأزهر أ / إبراهيم أحمد السبد إبراهيم

" تجربة التعليم المفتوح فى مصر دراسة تقويمية لتجربة التعليم المفتوح بكلية التجارة -

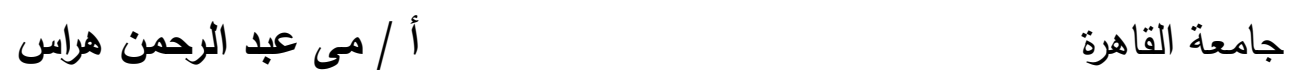


الإعلان العالمى بشأن التعليم العالى للقرن الحادى والعشرين فعاليات المؤتمر القومى السنوى العاشر "العربى الثانى" (جامعة المستقبل فى الوطن العربى) ديسمبر ب . . r. أ.د// على السيد الشخيبى

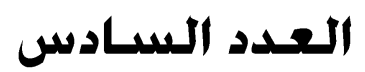
كلمة الافتتاح دراسات ويحوث "التحالفات والثراكات بين الجامعات والمؤسسات الانتاجية (مدخل لتطوير التعليم د/ يوسف سيد محمود

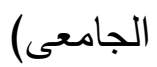
الجوانب الأساسية لتقويم الطالب المعلم من وجهة نظر المشرفين والمعلمين المتعاونين د/ عبد اللطيف بن حسين فرج

" التعليم والمجتمع العلمى فى ضوء التحديات المعاصرة "دراسة تحليلية د/ سعيد إبراهيم عبد الفتاح طعيمه

تأثير برنامج تدريبى باستخدام الموانع على قلق الامتحان والأمان النفسى ومستوى إنى د/ نادية عبد القادر أحمد الأداء على أجهزة الجمباز د/ رجاء أحمد عيد "Co operative Learning" ملخصات رسائل علمية "استقال الجامعات "دراسة للواقع والممكن من خلا آراء اعضاء هيئة التدريس د/ عبد العزيز الغريب مجاهد والطلاب دور التعليم العالى فى التمايز الاجتماعى في مصر د د/دينا إبراهيم أحمد جمال الدين ملف العدد "قواعد تشكيل والاجراءات المنظمة لسير العمل باللجان العلمية الدائمة " الدورة د. حسن طنطاوى

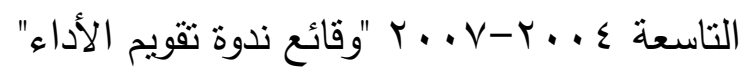


أ.د. على السيد الشخيبى مقدمة العدد دراسات ويحوث معلم محو الأمية وتعليم الكبار : اختياره، إعداده، تدريبه، تقويم أدائه" مركز تطوير التعليم الجامعي وجامعة عين شمس ولئ

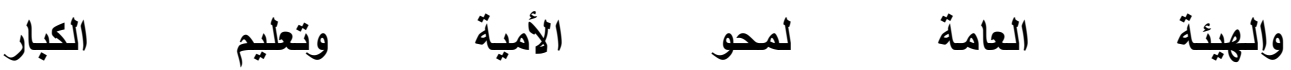
التعليم المستمر وتكنولوجيا التعليم بحث مرجعي أدم/ أحمد كامل الحصرى علاقة مهارات ما وراء المعرفة بأهداف الإنجاز أسلوب عزو الفشل لاى طلاب

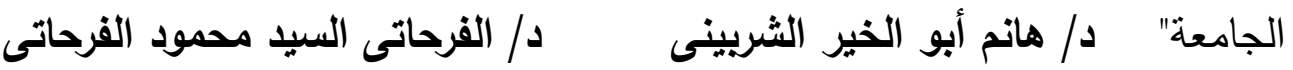
دور التربية فى مواجهة تداعيات العولمة" على الهوية الثقافية أ.د// حمدى حسن عبد الحمبا المحروفى

تأثنر الألعاب الشعبية بمصاحبة مثيرات بصرية وسمعية على النشاط الزائد وبعض المتغيرات البدنية للأطفال ذوي نقص الانتباه وفرط الحركة" د// زينب محمد أحمد الإسكندرانى

مشكلات التعليم الثانوى العام للبنات بمدينة الرياض بالمملكة العربية السعودية كما

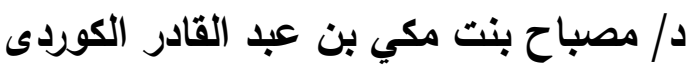
تراه المعلمات ملخصات رسائل علمية فعالية برنامج تربوى مقترح لتدريب المدرسين المساعدين والمعيدين بكليات جامعة الأزهر وأثزه على تتمية بعض مهارات التدريس واتجاهاتهم نحو مهنة التدربس" لرئ د/ رجاء محمود محمد عثمان

دور الجامعة الفلسطينية بغزة فى تتمية النسق القيمى لدى الطلبة" د/ هدى أحمد خليل درياش 
توصيات ندوة جامعة عين شمس فى خدمة المجتمع وتتمية البيئة "الواقع والمأمول" اصدرات المركز. العدد الثناهن

أ.د. على السيا الشخيبى مقدمة العدد

دراسات ويحوث "تقييم أداء الأستاذ الجامعي في ضوء معايير الجودة بحث مرجعي د. نادية حسن السبا على مرجي

"تأثير البطالة على الانتماء لاى الثباب الجامعي بصعيد مصر" د. عبد المعين سعد الدين هندي

"توجهات التتاول الصحفي لقضية الجامعات الخاصة في مصر خلال العامين د. سامية يوسف صالح

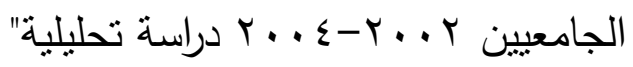
الثراكة بين المدارس والجامعات والتتمية المهنية للمعلمين في مصر" د. نهلة عبد القادر هاثم

عوامل إقبال شباب الخريجين على برنامج التدريب التحويلي وإحجامهم عنه " د/ إيمان محمد عارف

"تأثنر برنامجيين للتمرينات مختلفة المقاومة على المستقبلات الحسية وبعض المتغيرات الكيميائية ومستوى الأداء المهارى لبعض الوثبات في التمرينات الإيقاعية" د/ سلوى سيا موسى د/ وفاء السيد محمود إعداد أ/ سناء أحمد كمال ملخصات رسائل علمية أداء الجامعات في خدمة المجتمع وعلاقته باستقلالها دراسة مقارنة في جمهورية مصر العربية والولايات المتحدة الأمريكية والنرويج داء عبد الناصر محمد رشاد 
العوامل الأكاديمية المرتبطة بالرضا الوظيفي لأستاذ الجامعة دراسة ميدانية على د/ سناء أحمد كمال عبد السلام

كليات التربية"

ملف العدد

شباب وتتعليم

الثباب والتعليم وحصاد عام من القضايا" أين جامعاتتا بين أفضل . .0 جامعة في بقلم لبيب السباعي

أ.د/ على السيد الشخيبى

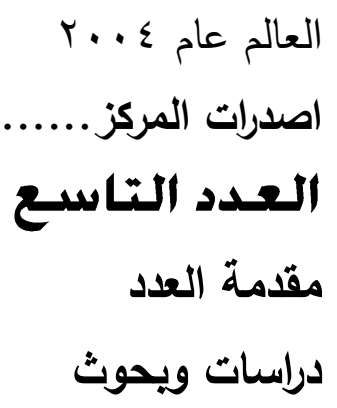

متطلبات إعداد المعلم في ضوء التحديات العالمية د. سهير محمد صادق شريف

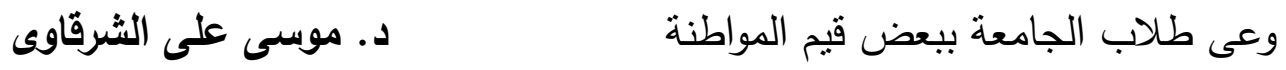
فعاليات برنامج ترويحى حركى اجتماعى على تتميه المهارات الاجتماعية وخفض الثعور بالخجل لدى الأطفال بمؤسسات الرعاية الاجتماعية في مرحلة الطفولة د. منى عبد الفتاح لطفي

المتأخرة

الضغوط المهنية لمدربى الجودو وعلاقتها بمفهوم الذات د. فايزة احمد محمد خضر فئر تأثنير استخدام تدريبات التصادم على كثافة العظام وعلاقته بمستوى الأداء المهارى د. دالة نبيل يحى الاء الهيل لدى لاعبات الجودو إعداد: أ. سناء احمد كمال ملخصات رسائل علميه تطوير الأداء الإدارى في كليات التربية بجامعة قناة السويس في ضوء إدارة الجودة أ / عبير فتحى محمد ابو سليمه الثناملة 

د. خالد محسن ثابت الجرادى

ملف العدد

شباب وتعليم

استمرار غياب الجامعات المصرية والعربية عالميًا وأفريقيا اصدرات المركز ... العدد العـاشثر

أ.د / على السيا الشخيبى

مقدمة العدد

دراسات ويحوث

مدى وعى طلاب الدراسات العليا بالتربية المعلوماتية د/ إيمان عبده حافظ عبد الصمد تأثثير برنامج تعليمي مقترح لبعض مهارات الحركات الأرضية على مستوى الأداء

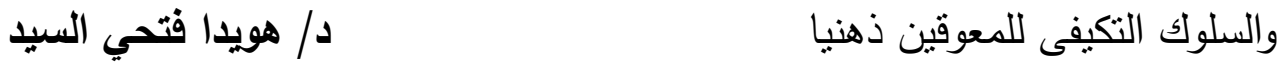
التخطيط لإنشاء جامعة أهلية فى المملكة العربية السعودية د د/ جواهر أحمد قناديلى ديلى تأثنير برنامج تدربيي لتتمية بعض المهارات النفسية على هرمونات الكاتيكولامين وبيتاأندروفين ومستوى الأداء المهارى لرياضة المبارزة

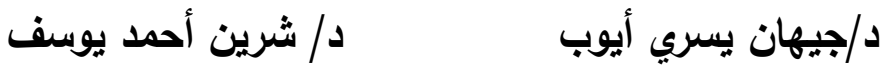
تقويم أداء جامعة الأقصى بغزة كخطوة على طريق تحقيق جودتها الثاملة د/ ناجى رجب سكر

إعداد: أ. سناء أحمد كمال ملخصات رسائل علمية تخطيط سياسات التعليم العالى فى مصر فى ضوء متغيرات الاقتصاد الحر د/ لمياء محمد أحمد السيد كفاءة التعليم الجامعى فى ضوء بعض المتغيرات العصرية د/ ماهر أحمد حسن 
البيان الختامي للمؤتمر القومي السنوي الثاني عشر (العربي الرابع) نظوير أداء الجامعات العربية في ضوء معايير الجودة الثاملة ونطم الاعتماد ديسمبر ه . . ب.

أ.د/ على السيد الشخيبى

$$
\begin{aligned}
& \text { اصدرات المركز.................. } \\
& \text { العدد اللحادى عشير }
\end{aligned}
$$

مقياس تقدير الاحتياجات التدريبية لأعضاء هيئة التدريس في مؤسسات إعداد المعلمين بالمملكة العربية السعودية في ضوء مفهوم الجدارة

د/ أسامة ماهر حسين

تصور مقترح لتهيئة خريجى مرحلة التعليم الثانوى العام لسوق العمل د/ أمال سبد محمد مسعود

تأثير برنامجين مختلفى الثدة على بعض عوامل التجلط فى الدم للاعبات ألعاب د/ هالة على مرسىى القوى. دور الإدارة فى مواجهة العنف فى مدارس التعليم الثانوى العام. د/ نجدة إبراهيم على سليمان تأثنير الكارتتين كأحدى المكملات الغذائية على بعض المتغيرات البيوكيميائية ومكونات الجسم وتحسين مستوى الأداء فى السباحة

د/ عبير عبد الرحمن شديا د/ أمل محمد أبو المعاطى عمر ونسين

إعداد: أ. سناء أحمد كمال ملخصات رسائل علمية

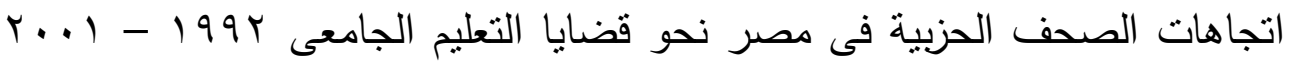
د/ هشام يوسف مصطقى 
تصور مستقبلى لتطوير دور الوحدات ذات الطابع الخاص بالجامعة لخدمة المجتمع. د/ سماح زكريا محمد

ملف العدد

توصيات المؤتمر العلمى السنوى الرابع عشر للجمعية المصرية للتربية المقارنة والإدارة

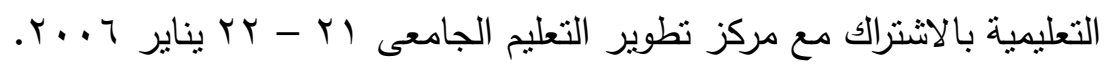
العدد الثانى عشر:

أ.د/ على السيد الشخيبى

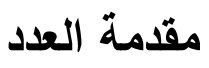
دراسات ويحوث جاهزية الجامعات السعودية لاستخدام إدارة الجودة الكلية كما يراها أعضاء هيئة

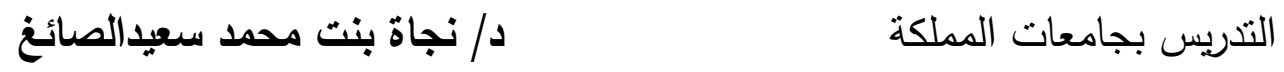
تقويم أداء عضو هيئة التدريس من وجهة نظر طالبات كلية التربية للبنات بالرياض.

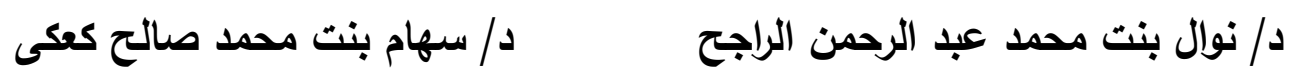
التحول فى الصيغة التقليدية للجامعة: رؤية وصفية تحليلية. د/ نجوى يوسف جمال الدين

استراتيجية مقترحة لتفعيل نموذج التعلم المتنقل M-Learning فى التعليم / تعلم اللغة الفرنسية كلغة أجنبية فى المدارس الذكية فى ضوء دمج تكنولوجيا المعلومات

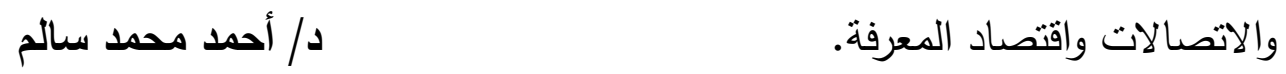
متطلبات تهيئة البيئة المدرسية لتحقيق مهارات التعلم الذاتى والمستمر لدى تلاميذ

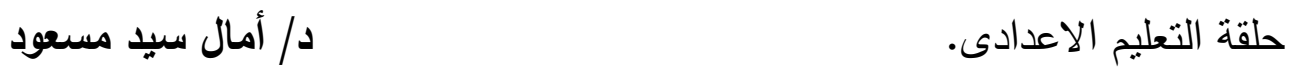
تتمية قيم المواطنه لدى تلاميذ التعليم الأساسى فى ضوء خبرات بعض اله

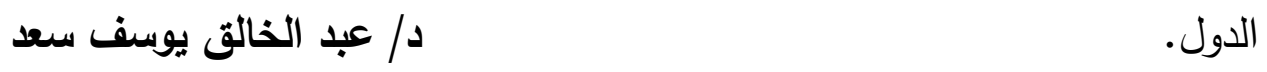


تطوير إدارة كليات التربية بالجمهورية اليمنية فى ضوء مدخل إدارة الجودة الثاملة.

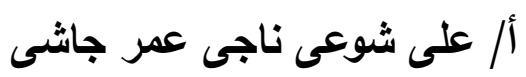

روئة مقترحة لتطوير التعليم العالى التكنولوجى فى مصر •

أ/ أحمد محمد عبد العزيز

ملف العدد

بيان بالأبحاث المنشورة بؤتمرات المركز (من الأول سبتمبر ؟99 1 الى الثانى عشر

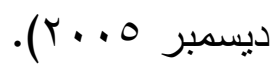

اصدرات المركز................

العدد الثنالث عشثر

أ.د/ على السيد الشخيبى

مقدمة العدد

كشاف المجلة من العدد الأول إلى العدد الثانى عثر

$$
\text { دراسات ويحوث }
$$

مساعدات الاتحاد الأوربى للتعليم الجامعى المصرى " دراسة تقويمية “. د/ على عبد الرؤوف نصار

د/ جمال أحمد السيسى

الأخلاق المهنية لأخصائى شئون التعليم والطلاب بالجامعة.

د/ أشرف عرندس حسين

د/ صبحي شعبان شرف

لد / هدى حسن حسن

البعد المستقبلى لبعض قضايا الفكر التربوى

دراسة تقويمية لنمط التعليم فى الجامعة العربية المفتوحة. لبعلئ

د/ صفاء أحمد محمد شحاتة

إدارات التطوير ودورها فى التتمية المهنية المستدامة لأعضاء هيئة التدريس. د/ حياة بنت محمد بن سعد الحربي هله 
إعداد: أ. سناء أحمد كمال

ملخصات رسائل علمية

دراسة مقارنة لنظم التعليم الممتد لبعض الجامعات الاجنبية وإمكانية الإفادة منها فى د/ شريف عبد الله سليمان حسن

الجامعات المصرية

الانتاجية العلمية لأعضاء هيئة التدريس السعوديات بكليات التربية للبنات بالمملكة العربية السعودية "دراسة تقويمية

د/ هدى حسن حسن

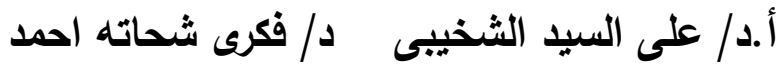

ملف العدد

البيان الختامي للمؤتمر القومي السنوي الثالث عشر (العربي الخامس) بعنوان: " الجامعات العربية فى القرن الحادى والعشرين: الواقع والروئ " العدرات المركز ............ أ.د/ على السيد الشخيبى

مقدمة العدد كثاف المجلة من العدد الأول إلى العدد الثالث عثر دراسات ويحوث

واقع التتمية المهنية لأعضاء هيئة التريس المصربين المعارين لبعض دول الخليج

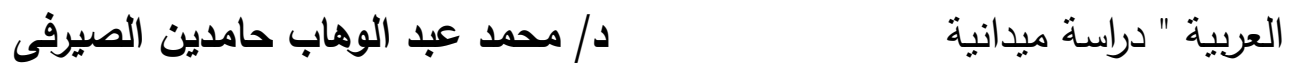
مستوى الدافعية للإنجاز وعلاقته بالتحصيل الدراسي لدى طلبة المرحلة الإعدادية من أبناء ضحايا عمليات الأنفال ـ فاقدي الأب ـ وأقرانهم أبناء الآخرين أ.م.د/ عمر إبراهيم عزيز مدخل المدرسة من أجل العمل وتطبيقاته في التعليم الثانوي باستراليا وجمهورية مصر

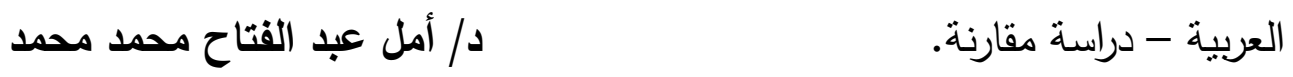


مدى ممارسة أعضاء هيئة التدريس في جامعة تعز لأدوارهم الإرشادية من وجهة د/ أنيسة دوكم

نظرهم ومن وجهة نظر الطلبة السياسات البحثية بالجامعات المصرية رؤية تحليلية نقدية. د/ رمضان أحمد عيد حسين إعداد: أ. سناء أحمد كمال ملخصات رسائل علمية دراسة مقارنة لبعض الخبرات الأجنبية فى تدويل التعليم الجامعى وإمكانية الإفادة منها أ/ أمانى محمد محمد حسن نصر فى جمهورية مصر العربية. مفهوم الهوية الثقافية وتداعياته فى الفكر التربوى المصرى المعاصر : دراسة نقدية.

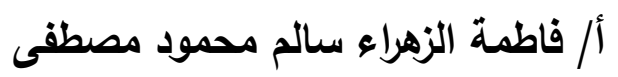

ملف العدد هل يحتاج العلماء الى نظام للأخلاقيات المهنية؟ Do Scientists Need a Professional Ethics?

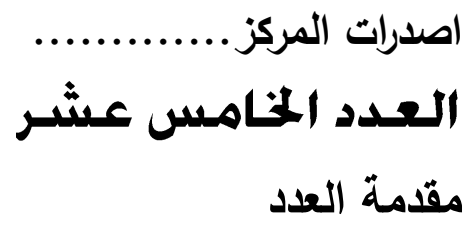

أ.د/ على السبد الشخيبى مقدمة العدد كثاف المجلة من العدد الأول إلى العدد الرابع عشر دراسات ويحوث

مستوى الوعي البيئي لدى طلاب التعليم الأساسي بكلية التربية جامعة المنوفية د/ أحمد محمود عياد

التنمية المهنية للقيادات التربوية لإدارة مدرسة المستقبل بدول الخليج العربي في ضوء

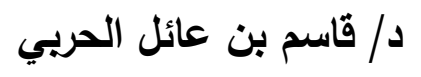
القيادة التحويلية نماذج مقترحة لتحسين التعليم الجامعى المفتوح فى مصر ". أ. د. محمود فتحى عكاشة أ. سهير محمد حوالة 
التدريب على تكنولوجيا المعلومات وتمكين المرأة فى ضوء المتطلبات التربوية للعمل د/ إيمان محمد عارف

في مجتمع المعرفة " تقويم الممارسات التربوية لأعضاء هيئة التدريس (جامعة أم القرى: دراسة حالة) د/ فائقة بنت عباس محمد سعيد

1- Environmental Awareness, Comparison among Egyptian and

Arab Students.

Prof. Sana Yousef El Daba

Dr. Hossam Altaher

2- Evaluating the first standard-based English language textbook in Egypt: Hand-in-Hand series 1- 3

Dr. Safaa Abdallah Hassan Eissa

إعداد: أ. سناء أحمد كمال

ملخصات رسائل علمية تطوير نظام التتمية المهنية لمديرى المدارس الثانوية بالمملكة العربية السعودية فى

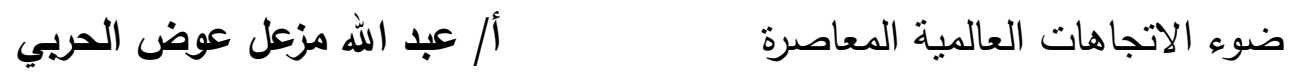
مفهوم الهوية الثقافية وتداعياته فى الفكر التربوى المصرى المعاصر " دراسة نقدية " أ/ فاطمة الزهراء سالم محمود

ملف العدد حقيبة تدريبية لتطوير كفايات رؤساء الأقسام بالجامعات العربية مركز تطوير التعليم

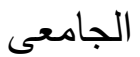

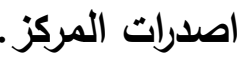


كشاف المجلة من العدد الأول إلى العدد الخامس عشر دراسات ويحوث

واقع الكفايات التدريسية اللازمة لمعلم علم الأجتماع فى ضوء المعايير القومية فى د/ امال احمد اسماعيل مصر للمرحلة الثانوية "دراسة تقويمية د/ خالد بن على بن عبدان الغامدى القراءات التقسيربة مفهومها، انواعها الايمقراطية من وجهة نظر الطالب معلم الفلسفة دراسة وصفية د د/ سعاد محمد عمر الخطاء الثائعة لاى قيادات الإدارة المدرسية من وجهة نظر المعلمين كمدخل مقترح

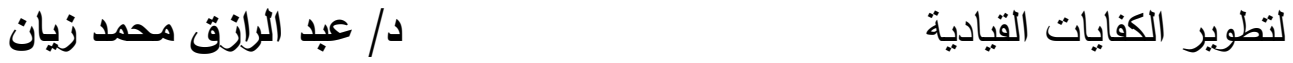
التوسع فى بيع التقسيط وآثاره الاقتصادية مع التطبيق على بعض المصارف السعودية د/ فهد بن عبد الله الشريف

فاعلية استخدام مدخل الطرائف التاريخية فى تدريس التاريخ على التحصيل وتتمية بعض مهارات الفهم القرائى والاتجاه نحو مادة التاريخ لاى تلاميذ المرحلة الاعدادية د / فايزة احمد الحسينى مجاهد

فاعلية برنامج اثرائى فى التربية البيئية فى تتمية مهارة اتخاذ القرار لدى الطلاب

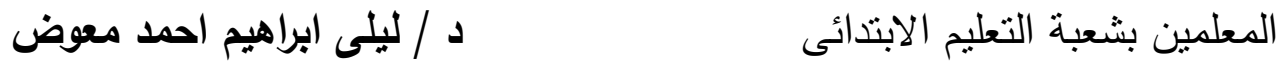
1- L'Utilisation du Recit Litteraire Pour Developper Quelques Competences de L'Expression E'crite chez les Futurs Maitres

\section{Dr. Abdul Nasser Cherif Mohammed ملخصات رسائل علمية} المقاومة فى النظرية النقدية وتوظيفها التربوى فى التعليم المصرى الباحثة / دينا ابراهيم احمد جمال $r \mu$ 
التخطيط الثبكى لإتخاذ القرارات التربوية الخاصة بالأبنية التعليمة " التعليم الأساسى الباحث / رأفت عبدالماجد قويس له بـ اله

كحالة

ملف العدد

البيان الختامى للمؤتمر السنوى القومى الرابع عشر

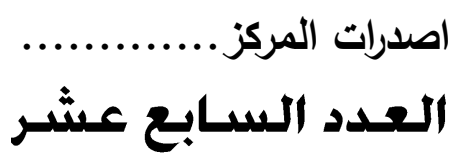

أ.د / سعيد إبراهيم طعيمة

مقدمة العدد

كثاف المجلة من العدد الأول إلى العدد السادس عثر

دراسات ويحوث

التعليم الجامعي الألماني بين دينامية التحول وتقافة التميز (نظرة تحليلية) د/ أحمد نجم الدين عيداروس

الأبعاد التربوية للمشكلة السكانيـة “الواقع وسيناريوهات المستقبل"

د/ دنسان أحمد رضوان

مدى استخدام معلمات العلوم مهارات التفكير المنظومي في تدريسهن لمقررات العلوم في الصف الأول الثانوي بمحافظات منطقة مكة المكرمة د/ خديجة محمد سعيد جان أثر العولمة الثقافية على مفهوم المواطنة لدي الثباب الفلسطيني [دراسة استكثافية] د/ صلاح الدين إبراهيم عطية حماد

دور منظمات المجتمع المدني في إثباع الاحتياجات التربوية للطفولة المتأخرة في الريف (دراسة ميدانية مطبقة علي العاملين بجمعيات ثتمية المجتمع ومراكز الثباب

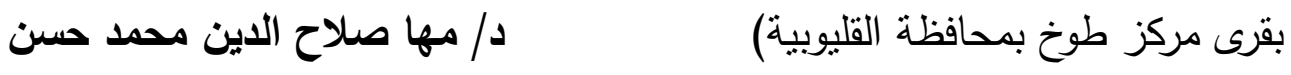


1- Production dDun Livre Electronique Proposé via Internet en Didactique du FLE à la Lumière de IDApplication de la Technologie de IDApprentissage Electronique pour les Etudiants des Facultés de Pédagogie

Dr. Ahmed Mohamed Salem ملخصات رسائل علمية الهوية الثقافية ومتطلبات تتميتها لدى طلاب الجامعة" الباحث / محمد سيد شباسى تصور مستقبلى للتعليم ما قبل المدرسي فى مصر باستخدام أسلوب التحليل البيئى الباحثة / إيمان محمد شوقي sowt Analysis

$$
\text { (( التعليم الصناعي وحتمية التطوير)(ال) }
$$

ملف العدد

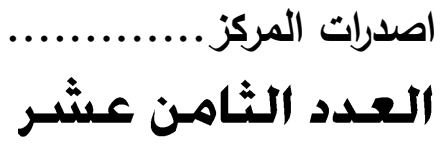

أ.د/ سعيد إبراهيم طعيمة

مقدمة العدد

كشاف المجلة من العدد الأول إلى العدد السابع عشر دراسات ويحوث

البنية العاملية لمقياس الدافعية الأكاديمية (الداخلية والخارجية) وعلاقتها باستراتيجيات

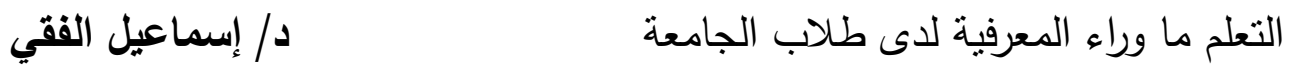
أنماط المشكلات الطلابية في مراحل التعليم العام في ضوء بعض المتغيرات

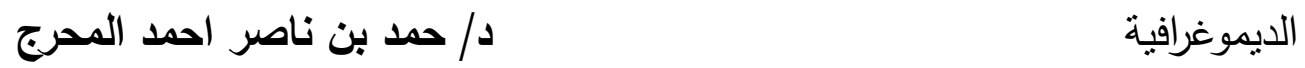
واقع تتميـة التربية من أجل المواطنـة فى المدارس الثانوبـة بمصر فى فى ضوء

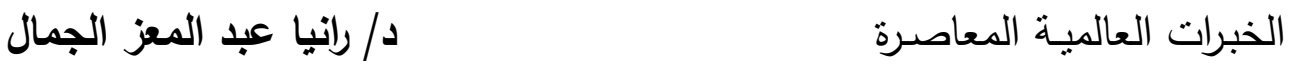
واقع التعليم في كتاتيب مدينة غزة منذ النكبة 9 ـ ام وحتى •97 ام د. زياد بن علي بن محمود الجرجاوي 
وحدات التدريب والتقويم في مدارس التعليم العام والفني بمحافظة الثرقية دراسة د/رجب عليوة على حسن بلن

تقوبمية في ضوء أهدافها ثقافة الحوار لدى طلاب كليات التربية في مصر (دراسة ميدانية) د. فاطمة على السعيد جمعة مبهة

\section{ملخصات رسائل علمية}

تربية القلب في الفكر الإسـلامي (دراسة تحليلية نقدية)

أ/ السيد صبحي متولي النحراوي

تقويم برامج تدريب موجهي الحلقة الأولى من التعليم الأساسي في ضوء الاتجاهات

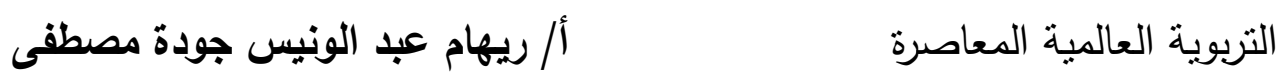
ملف العدد

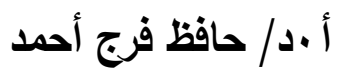

(أهمية الحوار والإقناع فى البحث العلمي)

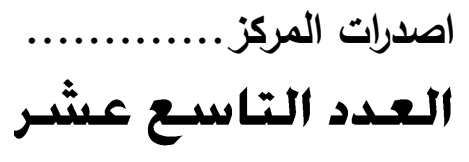

كشاف المجلة من العدد الأول إلى العدد الثامن عشر

دراسات ويحوث

الأفكار اللاعقلانية وعلاقتها بالتكيف الأكاديمي لاى طلاب جامعة الإمام محمد بن د/ صلاح العريني

سعود الإسلامية المتغيرات المجتمعية المؤثرة في المكانة الاجتماعية لعضو هيئة التدريس الجامعى بمصر ، وأبرز التحديات التى تواجهه د/ محمد أحمد إسماعيل د/ باسنت فتحي محمود

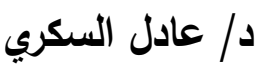
نظرية التعليم عند إكسينوفون 
دراسة مقارنة لخبرات بعض الدول في تحويل الجامعة إلى منظمة نعلم وإمكانية د/ سامي عمارة

الإفادة منها في مصر د الد / فتحي عثيبة تحليل مواقف أعضاء الهيئة التعليمية والإدارية من تطبيق إدارة الجودة الثاملة (كلية د/ فوزية صالح الشمري التربية الأقسام العلمية كنموذج) إدارة المواهب مدخل لتفعيل الانتماء التتظيمي لأعضاء هيئات التدريس بالجامعات

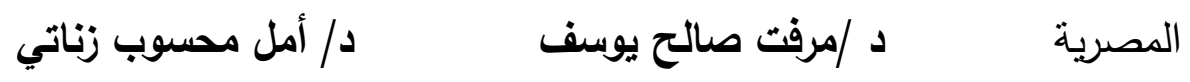
واقع المكون الوجداني ومنطلبات تفعيله بمنظومة الإعداد التزبوي للمعلم من وجهة د/ أمال محمد حسن عتيبة نظر الطالبات المعلمات

THE EFFECT OF EF TEACHING COMPETENCIES ON THE ACHIEVEMENT OF THE SECONDARY SCHOOL STUDENTS IN THE LIGHT OF THE NATIONAL STANDARDS

داطفمة أحمد محمد مغربي ملخصات رسائل علمية أ/ باسنت فتحي محمود الأبعاد المجتمعية لتطور كلية التربية التحولات في الأنساق القيمية لأعضاء هيئة التدريس بالجامعات المصرية " دراسة أ/ مصطفى أحمد علي أحمد تحليلية استشرافية " ملف العدد - م

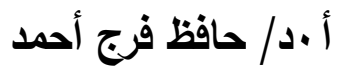
(أهمية الحوار والإقناع فى البحث العلمي) العدد العشيـرون أ.د// آمال عبد الله خليل

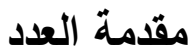
كشاف المجلة من العدد الأول إلى العدد التاسع عشر دراسات ويحوث دور كلية التربية النوعية جامعة المنوفية في خدمة المجتمع المحلي د/ إيمان حمدي محمدعمار rv 
معايير تميز الآداء البحثي في الجامعات العربية"دراسة تحليلية" د. عبد الناصر عبد الرحيم فخرو

استخدام الأساليب السردية في برامج كليات التربية بالجامعات المصرية: الأهمية،

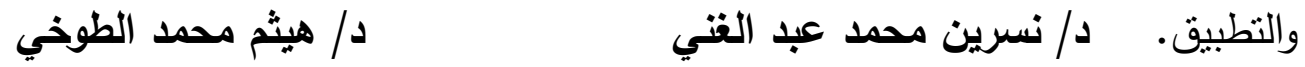
اللعب الدرامي الاجتماعي: روية جديدة للتعلم في رياض الأطفال د د/ إيمان النقيب تصور مقترح لمقرر في الإملاء للصف الأول الإعدادي ودراسة أثزه، وأثز استخدام التخذية الراجعة في تدريسه في علاج الأخطاء الإملائية لدى التلاميذ الإي د / سناء محمد حسن أحمد

إدارة المعرفة أسسها ومفاهيمها في سورة الكهف ماجدة إبراهيم الجارودي القصة في الحديث النبوي رحاب عبد السلام عبد المؤمن مكي تمويل التعليم الجامعى من وجهة نظر المستقيد المباشر من الخدمة التعليمية د. ن اجنى عبد الوهاب هلال

ملخصات رسائل علمية فاعلية برنامج مقترح لإعداد الطالب المعلم بقسم الجغرافيا بكلية التربية في ضوء

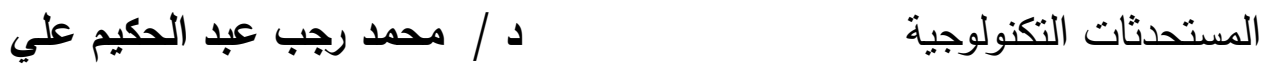
أثز برنامج قائم على تكامل المعرفة لتمية الأداءات المهنية لدى الطالب المعلم بشعبة د / دعاء عبد الكريم عبد الرجال اللغة الألمانية بكلية التربية ملف العدد

البيان الختامي للمؤتمر القومي السنوي الخامس عثر (العربي السابع) " نحو خطة استراتيجية لتطوير التعليم الجامعى العربى " اصدرات المركز .. 
أ.د / آمال عبد الله خليل

مقدمة العدد

كشاف المجلة من العدد الأول إلى العدد الواحد والعشرين

دراسات ويحوث

الدور التربوي الدعوي لبعض مساجد تورنتو للجالية المسلمة في كندا د. حليمة علي مصطفى

العولمة ودور النظرية التربوية الإسلامية في تفسيرها

د. إكرام بنت كمال بن عوض المصري

فعالية برنامج إلكترونى لتتمية الوعي بالملوثات فى البيئة المنزلية لدى طلاب كلية

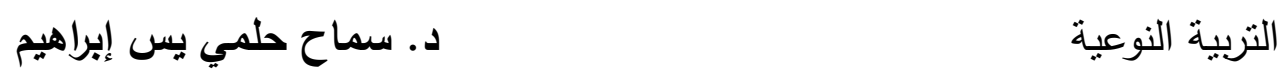

استخدام الإنترنت لدى عضوات هيئة التدريس في كليات جامعة أم القرى واتجاهاتهن

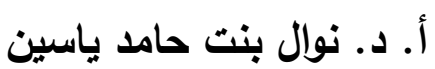

نحوه

ملخصات رسائل علمية

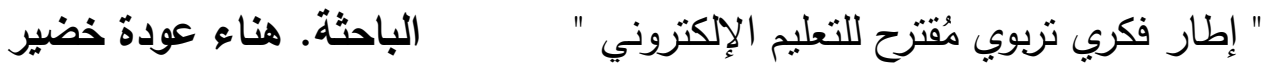
تتمية بعض متطلبات حماية النفس من خلال تدريس البيولوجى لطلاب المرحلة الباحث. محرم يحيى محمد 
أ.د// آمال عبد الله خليل

مقدمة العدد

كشاف المجلة من العدد الأول إلى العدد الحادي والعشرين دراسات ويحوث

متطلبات تطويرالتعليم الجامعي الزراعي المفتوح لتفعيل التنمية بمجتمع شمال سيناء " د. محمد عبد الوهاب حامد

دراسة مبدانية "

فعالية استخدام الوسائط المتعددة في تتمية بعض المفاهيم العلمية لدى أطفال ما قبل

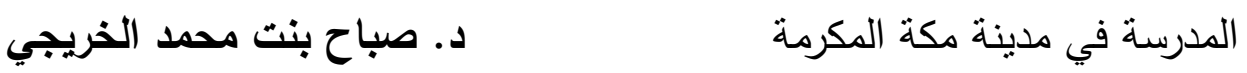
مدارس بناء المهارات الحياتية وتتميتها في المملكة العربية السعودية للقرن الحادي د. نجلاء علي مصطقى والعشرين د. دوف بنت ناصر التميمي اتخاذ القرار لدى مسئولى الإدارة العليا التربوية وإمكانية تطويره (رؤية مقترحة) د. عقيل محمود رفاعي

ملخصات رسائل علمية " تخطيط التغيير المؤسسى فى التعليم الجامعى المصرى فى ضوء متطلبات دمج تكنولوجيا المعلومات والاتصالات فى العملية التعليمية د. هناء عودة خضيري المدخل الجزيئي في منهج مقترح للبيولوجيبالمرحلة الثانوية وفاعليته في تتمية المفاهيم البيولوجية ومهارات التقكير والاتجاه نحو دراسة البيولوجيا د.محرم يحيى محمد ملف العدد البيان الختامي للمؤتمر القومي السنوي السابع عثر" العربي الثامن " اصدرات المركز ... 


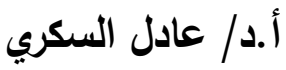

مقدمة العدد

كشاف المجلة من العدد الأول إلى العدد الثاني والعشرين دراسات ويحوث

تصورات المتعلمين عن استخدام ملف الإنجاز الإككتروني في التعلم والتقويم د. أحمد بن زيد آل مسعد

ممارسات إدارة المعرفة لدى القيادات الجامعية دراسة تطبيقية على جامعة الإسكندرية د. السيدة محمود إبراهيم سعد

برنامـج مقترح لتحقـق الاستثمار الأمنل للموارد المتاحةًأ. باسم زغلول الثحات بدوي تطوير عمليات إدارة المعرفة في الجامعات السعودية " دراسة ميدانية " د. سعاد بنت فهر الحارثي

التأثيرات الحضارية الإسلامية على الغرب الأوربي خلال الحروب الصليبية د. عبد العزيز بن راشد العبيدي

أ. لينا زياد صبيح

التعليم الجامعي ومجتمع المعرفة

دور شراكة الأسرة والمدرسة فى تعزيز الهوية الثقافية فى ضوء تحديات العولمة

أ. نازي محمد فتحي

ملخصات رسائل علمية

تطوير الكتاب المدرسي لمادة اللغة الألمانية كلغة أجنبية ثانية فى المرحلة الثانوية أ / أ هبه قتاوى إبراهيم صالح

بمصر

فعالية استخدام مدخل السير والتراجم في تتمية بعض القيم الاجتماعية لتلاميذ الصف الصفي أ / أمل محمد فرغلي أحمد الثاني الإعدادي ملف العدد

د. هناء عودة دليل ضوابط الملكية الفكرية اصدرات المركز... 


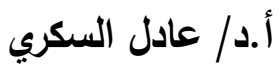

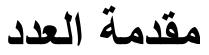

كشاف المجلة من العدد الأول إلى العدد الثالث والعشرين دراسات ويحوث

المصادر المفتوحة ودورها في بناء المعرفة د. ماجد حمايل د. إنشراح الجبريني "توظيف الفن الرقمي لتتمية الوعي الإدراكي ومفهوم العولمة للطالب قبل الجامعي وعلاقته بالهوية الثقافية والانتماء نحو القضية الفلسطينية" أ.م.د/ إيمان أحمد حمدي إمام

وحدة مقترحة لتضمين جوانب التراث الفلسطيني بكتب اللغة العربية بالمرحلة الإعدادية بجمهورية مصر العربية

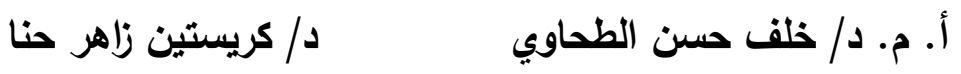

تطوير الأداء البحثي في الجامعات الناشئة في ضوء الثراكة المجتمعية والتشبيك ركي د / سامي عبد السميع رضوان

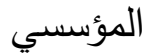

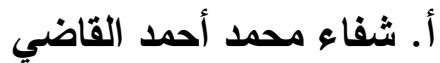

حماية الأطفال من سوء المعاملة والإهمال

التربية بالحوار بين المعلم والمتعلم من منظور إسلامي أ. طيبة عمر محمد العمودي Emploi de la Technique des Chapeaux de Réflexion Mélangée avec les Stratégies de Compréhension pour Développer Quelques Compétences de la Compréhension Critique chez les Futurs Maîtres de FLE Dr. Abdel Nasser Chérif Mohammed Les difficultés de l'apprentissage de la langue Française au Cameroun Dr Ali Moustafa Youssef Mahmoud

The Implementation of Actions and Reactions as Checked upon by Styles of Thinking : An Analytical Comparative Study 


\section{Dr. Mohammad A. Qasaimeh Dr. Yousof A. Qasaimeh.}

تطبيق الجودة الثناملة في المدارس الأهلية أ. منال بنت حسين بن حسن الحميدي تصور مفترح للجودة والاعتماد الأكاديمي لكلية التربية جامعة الأميرة نورة في ضوء د.نوف بنت محمد هضيبان الدوسري بعض التجارب العالمية. دور التربية الفنية فى تأكيد الهوية الثخصية لدى المراهقين الفلسطينيين المغتربين من د. هناء عبد الوهاب فريد

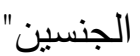

ملخصات رسائل علمية فاعلية برنامج إثرائى قائم على بعض الذكاءات لتتمية مهارات الجغرافيا لدى طلاب

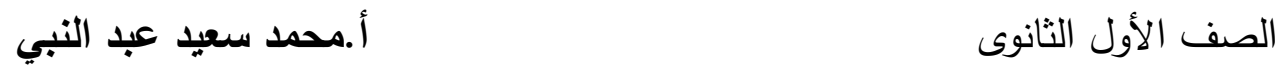
منهج مقترح فى الكيمياء للمرحلة الثانوية العامة بمصر فى ضوء مستويات معيارية

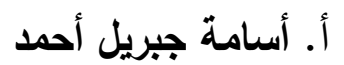

ملف العدد - م

روئة مستقبلية للتعليم قبل الجامعى فى مصر فى ظل تغيرات وتحولات د. يسري عفيفي عفيفي

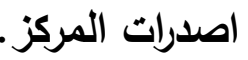 العدد اللخاهس والعشيرون مقدمة العدد}

أ.م.د/ زينب محمد حسن خليفة كشاف المجلة من العدد الأول إلى العدد الرابع والعشرين دراسات ويحوث "التعليم العالي والجامعي المصري بين معاول الهدم وأدوات البناء - دراسة تحليلية تقويمية على ضوء الاتجاهات العالمية "د. حمدي عبد الحافظ محمد تصور مقترح لتطوير برامج تدريب موجهي الحلقة الأولى من التعليم الأساسي في ضوء الاتجاهات أ . ريهام عبد الونيس جودة المياء

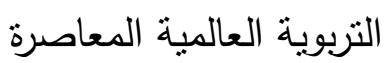


تفعيل دور كليات التربية بمصر في تحقيق الأمن التربوي لطلابها على ضوء ثورات

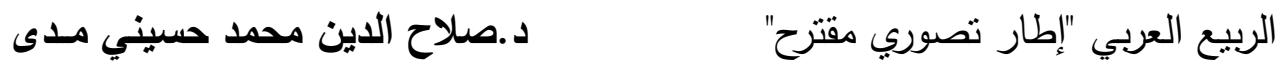

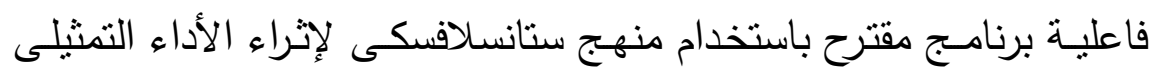
داطمة مبروك مسعود

فاعلية وحدة مقترحة لتدريس التاريخ باستخدام خرائط العقل في تتمية مهارات التفكير

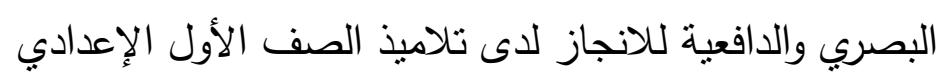
د. فايزة أحمد الحسيني مجاهد

صعوبات التعلم والقواعد النحوية والصرفية أ. هشام أيوب عبد العزيز أيوب ملخصات رسائل علمية فاعلية كتاب إلكترونى لعلاج صعوبات تعلم الرياضيات لدى تلاميذ المرحلة الابتدائية أ ـ محمود مصطقى عطية معايير تصميم الوسائط الفائقة التكيفية عبر الويب أ / شريف شعبان إبراهيم محمد أ.م.د / زينب محمد حسن ملف العدد استخدام الويب r فى التعليم اصدرات المركز................. العدد السسادس والعشـرون أ.م •د/ زينب محمد حسن مقدمة العدد كثاف المجلة من العدد الأول إلى العدد الخامس والعشرين دراسات ويحوث واقع ممارسة رئيسات الأقسام العلمية بجامعة الأميرة نورة بنت عبد الرحمن في مدينة

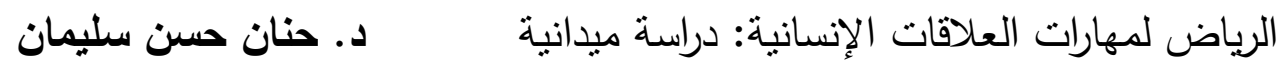


"روية مستقبلية لإعداد المعلم العربي في ضوء منطلّبات مجتمع المعرفة"

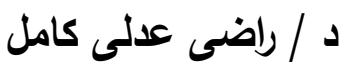

(دراسة حالة على محافظة أسوان)

د/ رجاء فؤاد غازى

القيم المربية في مسرحية " ليلي والمجنون "'" دراسة تحليل التعلم عند برهان الإسلام الزُرنوجي د / سارة بنت هليل دخيل الله المطيري ضوابط الدراسات المستقبلية في ضوء التربية الإسلامية دلفابي نموذجاً د. طلال عقيل عطاس الخيري

الأساليب التربوية المناسبة لعلاج بعض القيم السلبية لدى الثباب بمحافظة جدة د. محمد بن عمر أحمد المدخلي

(دراسة مبدانية)

نظام الساعات المعتمدة مدخلا مقترحا لتطوير منظومة التعليم الثانوى العام بمصر د. - دناء عودة خضرى

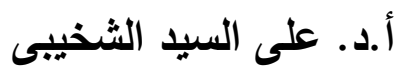 ملخصات رسائل علمية}

معايير تصميم الوسائط الفائقة التكيفية عبر الويب أ/شريف شعبان إبراهيم محمد فاعلية استخدام الألعاب الإكترونية على تتمية مفاهيم الرياضيات لدى أطفال ا ـ مروة سليمان أحمد سليمان

الصفوف المقلوبة مدخل لخلق بيئة تعليمية شاملة أ.م .د / زينب محمد حسن خليفه اصدرات المركز 
كثاف المجلة من العدد الأول إلى العدد السادس والعشرين دراسات ويحوث

تصور مقترح لضبط وضمان الجودة فى كليات التنربية المعتمدة فى ضوء معايير

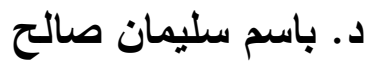

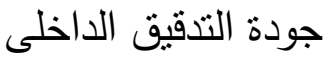

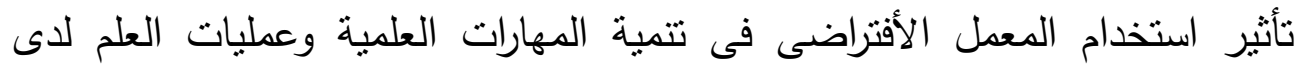

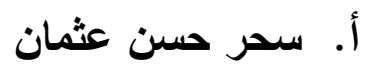

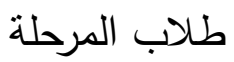
د. صباح عبد الله محمد فضل التصغير بين الأصالة والتجديد

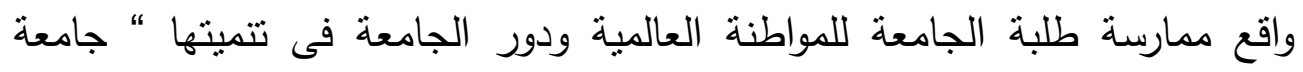

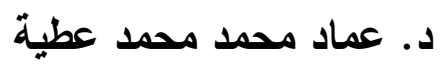

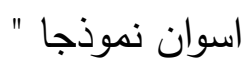

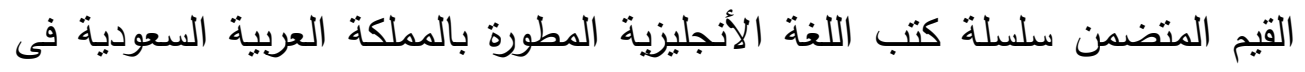

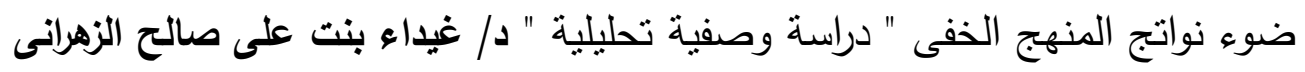
التوضيحات التربوية فى حفظ الأعراض على ضوء الهدى النبوى الثريف د. منال صالح عبد رب النبى الني

فاعلية المدخل الكلى للغة فنتمية الاداء الكتابى فى اللغة العربية لدى تلاميذ الصف

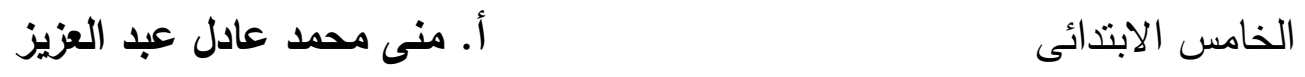
معوقات استخدام الدقرات الإلكترونية فى التعليم عن بعد فى ضوء معايير جودة

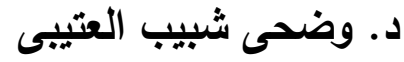
التعليم الالكترونى التي 
أثز توظيف المجتمعات الإفتراضية فى تقديم أنماط مختلفة من التغذية الراجعة فى

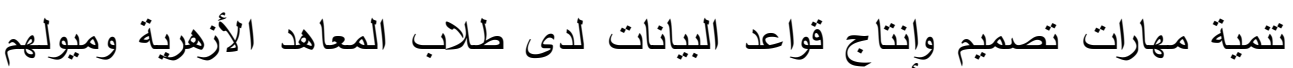
أ ـ محمد وحيد محمد سليمان نحوها فاعلية برنامج مقترح لإكساب طلاب تكنولوجيا التعليم مهارات إنتاج الصور المولدة أ. وليد محمد عبد الحميد دسوقى مهيد بالحاسوب ملف العدد

توصيات المؤتمر القومى السنوى الثامن عثر العربى العاثر بعنوان " تطوير منظومة الاداء فى الجامعات العربية فى ضوء المتغيرات العالمية المعاصرة "

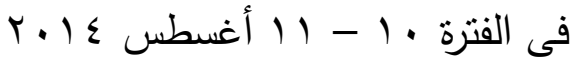

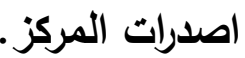
العدد الثاهن والعشئرون العزئ أ.م.د/ زينب محمد حسن مقدمة العدد كشاف المجلة من العدد الأول إلى العدد السابع والعشرين دراسات ويحوث

استراتيجيات تفعيل دور الجامعات المصرية في دعم الإنتاجية العلمية لأعضاء هيئة

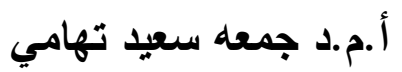
التدريس د.خديجة بنت محمد

الأمن الاجتماعي في ميزان العدل والإحسان الجيزانيدور الالتزام الديني في تحقيق الأمن النفسي" دراسة نظرية " أ ـ طيبة عمر محمد العمودي ثقافة الجودة الثاملة ودورها في تعزيز الأمن بالمجتمع د. خالا عبدالله الخزاعلة د. عدنان أحمد الورثان 
الأبعاد التربوية المتضمنة في الحوار من المنظور القرآنى وتطبيقاتها التربوية لدى طلاب كليات التربية في بعض جامعات جمهورية مصر العربية والمملكة العربية السعودية أ.م.د ـ محمد أحمد محمد إسماعيل عزة ياقوت ياقوت العزب أثز برنامج مقترح عبر الثبكة على تتمية مهارات استخدام المستحدثات التكنولوجية لاى مديري المدارس بالمملكة العربية السعودية. د/ عبير حسين عونى فرحات

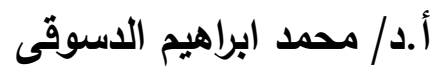
أ/محمد بن علي عياد العتيبي

"ثقوبم أداء الاكاديمية المهنية للمعلمين في ضوء أهدافها واستراتيجية مقترحة لتطويرها أ.م. د. . معوض حسن ابراهيم مرعى وسنى أ . هناء قاسم حسانين معايير ضبط المفردات وعلاقتها بالفهم القرائى ملخصات رسائل علمية برنامج لإعداد معلمي البيولوجيا في ضوء المتغيرات البيومعلومانية والبيوأخلاقية في أ. أماني محمد عبد الحميد أبوزيد

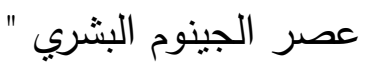
تصور مقترح لتوظيف شبكات الإعلام الاجتماعى فى توجيه طلاب الجامعة نحو أ. دينا خالا سليمان محمود المشاركة السياسية ملف العدد انجازات مركز تطوير التعليم الجامعى اصدرات المركز................ 
كشاف المجلة من العدد الأول إلى العدد الثامن والعثرين دراسات ويحوث

القيم التربوية المتضمنة من آيات الإحسان في القرآن الكريم وأساليب الأسرة في تتميتها "دراسة تحليلية". أماني بنت محمد بن محمد قليويي اتجاهات أعضاء هيئة تدريس جامعة سلمان بن عبد العزيز بمدينة الخرج نحو استخدام الأجهزة اللوحية في التدريس أمجاد بنت سعود بن حوتان التأصيل الاسلامي للتقوبم التربوب في ضوء توجيهات بعض آيات سورة القصص د. الهام عبدالوهاب مغربي

الآراء التربوية للأمام القرطبي من كتاب " جامع بيان العلم وفضله وما ينبغي في

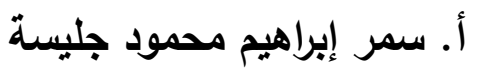
روايته وحمله" وتطبيقاتها معايير تصميم الوسائط الفائقة التكيفية عبر الويب أ. شريف شعبان إبراهيم محمد التربية وبعض قضايا المرأة فى كل من التشريع الإسلامي وبعض المواثيق الدولية د / مزة ياقوت ياقوت العزب موقف المجلات التربوية العربية من بعض القضايا الخاصة بدور كليات التربية في

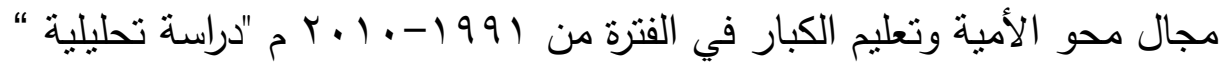
أ.م.د. محمد أحمد محمد اسماعيل

تحقيق مسار الكليات الإنسانية في السنة التحضيرية بجامعة الملك سعود لأهدافها من وجهة نظر أعضاء هيئة التذريس والطلاب الإبساء د.محمد عبد الله الزامل أ. عبد الله محمد عبد الله الأكلبي 
تطوير مناهج التاريخ في ضوء أبعاد الأمن المجتمعي والوعي بها وأثثر في تتمية بعض المهارات الاجتماعية والانتماء لدى طلاب المرحلة الثانوية

أ. أمل محمد فرغلي أحمد سبد

برنامج قائم على تقنية الواقع الافتراضى لتتمية المفاهيم الجغرافية لدى تلاميذ الصف

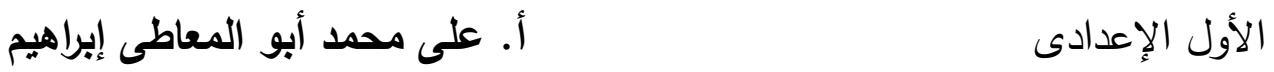

ملف العدد

بيان بالأبحاث المنشورة بمؤتمرات المركز من الثالث عشر نوفمبر ج +. بالى الثامن

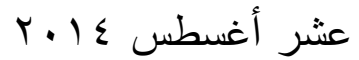
اصدرات المركز................ العدد الثلاثون

أ.م.د/ زينب محمد حسن

مقدمة العدد كشاف المجلة من العدد الأول إلى العدد التاسع والعشرين دراسات ويحوث متطلبات تطبيق بحوث الفعل فى مؤسسات التعليم قبل الجامعى بمصر ".

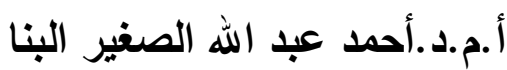

فاعلية التعليم المدمج في علاج صعوبات تعلم القواعد النحوية لدى تلاميذ المرحلة

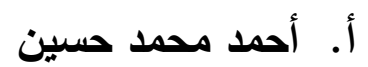
الابتدائية واقع التمكين الوظيفي لدى القيادات التربوية وعلاقته بمدى تحقيق الإدارة الرشيدة في

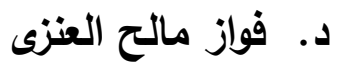
مدارس التعليم الثانوي العام بدولة الكويت د. منار محمد إسماعيل تقويم سياسات التعليم قبل الجامعي في مصر 
تفسير آيات من سورة مريم تفسيراً تحليلياً مع مقدمة عن إختصاص السورة بهذا الاسم أ. أ. ناهد محمد عياش به الاشم

جهود اعتماد إعداد المعلم بكلية التربية بين المشروعية والمشروعات

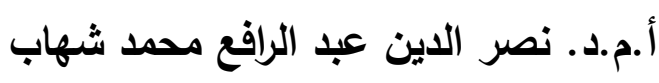

فاعلية إختلاف حجم مجموعات التشارك في العصف الذهني الإلكتروني لتتمية مهارات التفكير لاي طلاب نكنولوجيا التعليم أ. هنادي محمد أنور عبد السميع اثز استخدام استراتيجيات التدريس التفاعلي النشط على التحصيل الاجل لمقرر طرق تدريس شعبة الكيمياء لطالبات لكلية التربية جامعة أم القرى القي د. هنيه بنت عبد الله بن سراج سعداوي

ملخصات رسائل علمية

نموذج تصميم تعليمي مقترح للتعلم التشاركي قائم على نوظيف أدوات الجيل الثاني من الويب لتتمية الإنتاج الإبداعي في تكنولوجيا التعليم لدى الطلاب المعلمين بكلية أ / مروي سليمان أحمد سليمان

التربية بناء بيئة تعليمية قائمة على شبكات الوييب الإجتماعية وأثزها فى تتمية مهارات

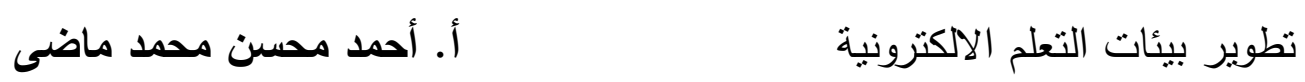
ملف العدد

توصيات المؤتمر القومى السنوى التاسع عشر العربى " الحادى عشر " بعنوان " التعليم

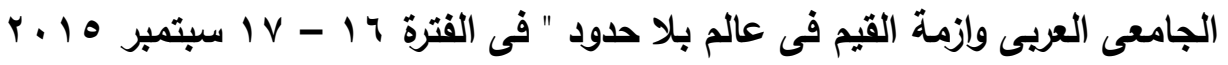
اصدرات المركز.............. 
واقع توظيف معلمات رياض الأطفال للتطبيقات التربوية في الأجهزة الذكية في التعليم أ.م.د. أماني بنت حمد بن منصور الشعيبي

التحليل القيمي لمضمون قصص الأطفال لبعض إصدارات الهيئة المصرية العامة للكتاب رؤية مقترحة لمواجهة ظاهرة الغياب المتكرر لطلاب المرحلة الثانوية الحكومية

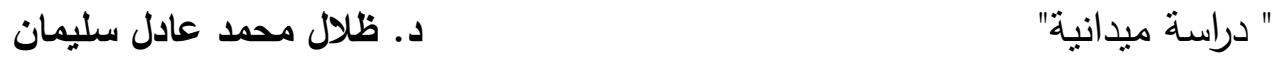
التطوير التظظيمي لكلية التربية جامعة عين شمس في ضوء منطلبات تحقيق ضمان د. لمياء محمد أحمد

الجودة "رؤية مستقبلية" - الجية التربية الوقائية للمؤسسات التربوية فى مواجهة التطرف الفكرى مونه أ.م.د. / محمد النصر حسن محمد

تصميم بيئة الكترونية مفترحة لنطوير نظام التعليم الجامعى المفتوح فى ضوء الخبرات

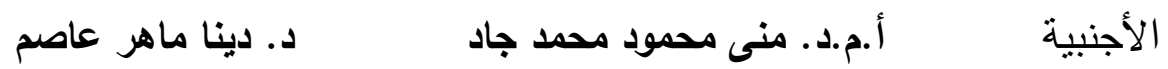
فاعلية استراتيجية توليفية لتتمية مهارات القراءة الإبداعية لدى تلاميذ المرحلة أ. مها رفعت صابر الإعدادية فاعلية التعلم الإلكتروني القائم على المشروعات في تنمية مهارات المقررات

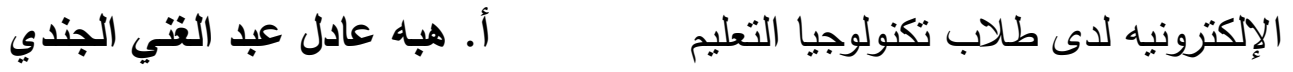


فاعلية الأنماط المختلفة للتفاعل ضمن الفصول الافتراضية فى نتمية مهارات التفكير الرياضى والميل نحو التعلم الرياضى لدى طلاب الثانوية العامة

أ. محمود مصطفى عطية

ملخص رسالة ماجستيز

فاعلية برنامج تدريبي قائم على المستحدثات التكنولوجية في تتمية المهارات الحياتية لذوي الإعاقة الذهنية القابلين للتعلم أحمد عبد النبي عبد الملك نظير ملف العدد

الحوسبة السحابية خدماتها ودورها في العملية التعليمية أ.د. زينب محمد حسن خليفة اصدرات المركز................. العدد الثنانى والثلاثون

أ.د// زينب محمد حسن خليفة مقدمة العدد كشاف المجلة من العدد الأول إلى العدد الحادى والثلاثون دراسات ويحوث سيناريوهات لإعداد الصف الثاني من القيادات التربوية في ضوء اتجاهات الفكر د. احمد محمد نبوى الإداري الحديث "روئة مستقبلية" ضمان جودة التعليم المفتوح مدخلًا لتحقيق متطلبات التتمية المستدامة د. زينب عبد التبي أحمد محمد

التنظير للمصطلح في الخطاب التربوي الإسلامي أ. السيد صبحي متولي النحراوي وجهة نظر معلمي مدارس المرحلة الابتدائية بمدينة الرياض د. ظلال محمد عادل سليمان في معايير الجودة الثاملة في التعليم 
المهارات السمعية اللازمة للتناميذ المكفوفين بالمرحلة الابتدائية أ. فاطمة السيد عبد العظيم أبوشوك

الموازنة فى الشعر العربى الموجه للأطفال بين الجوانب الوجدانية والمعرفية د. فاطمة مبروك مسعود

\section{ملخصات رسائل علمية}

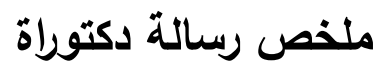

بناء بيئات إلكترونية قائمة على بعض أنماط الوكيل الذكي وقياس فاعليتها على التحصيل والاتجاه نحوها لاى التلاميذ الموهوبين منخفضي التحصيل بالمرحلة أ.أحمد عبد النبي عبد الملك نظير لين بحري

$$
\text { الإعدادية }
$$

ملخص رسالة ماجستير

فاعلية فصل إفتراضي في تحصبل التحلاميذ المعاقين سمعياً لمفاهيم الحاسب الآلي أ. مصطفى أمين إبراهيم عبد العال بالمرحلة الإعدادية

ملف العدد

E. Portfolioة ملفات الإنجاز الإلكتروني وتحسين العملية التعليمية أ.د. زينب محمد حسن خليفة 
أ.د / زينب محمد حسن خليفة

مقدمة العدد

كشاف المجلة من العدد الأول إلى العدد الثانى والثلاثون

دراسات ويحوث

التعليم الثانوي الصناعي وقطاع الصناعة في كل من الولايات المتحدة الأمريكية والمملكة المتحدة وفرنسا وإمكانية الإفادة منهم في مصر "دراسة مقارنة " د. احمد محمد نبوى حسب النبى

نقد مبادىء التربية الدولية من منظور التربية الأسلامية د / طالب بن صالح بن حسن

تتويع مصادر التمويل الذاتى للمدارس الحكومية فى مصر "دراسة ميدانية " د. ظلال محمد عادل سليمان

تطوير الأداء الإدارى للقيادات الجامعية فى ضوء مدخل ادارة التغير جامعة الأمير د. عبدالعزيز محمد على صفر سطام بن عبدالعزيز نموذجاً القيم التربوبة لدى طلاب كلية التربية أيلى احمد عبدالحكيم عبدالسلام أثز اختلاف نمط التعليم المدمج على تتمية التحصيل ومهارات التفاعل الإكتروني وبقاء أثز التعلم لدى طلاب تقنيات التعليم بكلية التربية د. محمد السيد السيد سليمان التربية من أجل السلام فى مواجهة ظاهرة العنف بالمدرسة الثانوية فى مصر أ.مروة أحمد محمد محمود

معايير إنتاج بيئة تعلم تشاركية قائمة على تطبيقات السحابة الكمبيوترية لتتمية أ. هشام أحمد إسماعيل الصياد مهارات إنتاج مستودعات البيانات إنثراف

م.د/عمرو محمد محمد أحمد درويش أ.د/منى محمود محمد جاد 
أثــر اختلاف أنمــاط العــوالــــ الإفتراضية ثـلاثيـةالأبعـاد علي التحصيل والتقكير البصــري لدي الطـلاب ذوي صعوبـات التعلم في مقـرر شبكـات الحــاسب أ. مصطفى امين ابراهيم عبدالعال

ملخص رسالة ماجستير مستويات تتور الطلاب المعلمين بكلية التربية شعبة التعليم الأساسى في تكنولوجيا أ. عمر سبي أحمد محمود

التعليم "دراسة تقويمية"

ملف العدد

E. Portfolio ملفات الإنجاز الإلكتروني وتحسين العملية التعليمية الجزء الثانى " ملف انجاز الطالب واساليب التقويم " أ.د. زينب محمد حسن خليفة

أ.د/ زينب محمد حسن خليفة

مقدمة العدد كشاف المجلة من العدد الأول إلى العدد الثالث والثلاثون دراسات ويحوث أثز استخدام استراتيجية مقترحة في ضوء نظرية الذكاءات المتعددة على تتمية التحصيل ومهارات حل المشكلات لدى تلاميذ المرحلة الإعدادية بليبيا أ. امنه ميلاد امحمد حسن الإعن بلن

تفعيل المشاركة الطلابية في انتخابات أندية الطلاب السعوديين بالمملكة المتحدة " د. عبد الله بن مزعل الحربي

رؤية مقترحة " 
رؤية تربوية مقترحة لمواجهة مخاطر شبكات التواصل الاجتماعي على القيم المجتمعية وأساليب الحوار المجتمعي في ضوء خبرتي الولايات المتحدة الأمريكية د. عماد عبد اللطيف محمود

فاعلية عناصر التعلم عبر الويب في تتمية مهارات تصميم المقررات الالكترونية لدى أ / ماجدة صبحي متولي البر

طلاب تكنولوجيا التعليم المهارات اللازمة لإستخدام الكمبيوتز اللوحى فى التذربس لدى معلمى مرحلة التعليم

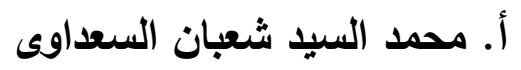

الاساسى

ملخصات رسائل علمية

ملخص رسالة دكتوراة

برنامج لإعداد معلمي البيولوجيا في ضوء المتغيرات البيومعلوماتية والبيوأخلاقية في

دـ ـ أماني محمد عبد الحميد أبوزيد عصر الجينوم البشري

ملخص رسالة ماجستير

فاعلية استراتيجية دروس الفروض والتجارب فى تصويب التصورات البديلة لبعض المفاهيم الكيميائية لدى طلاب الصف الأول الثانوى د ـ ـ عصام محمد سيد أحمد

ملف العدد

ظاهرة العنف الطلابى فى الجامعات المصرية: رؤية واقعية

أ. أد. صفية حمدى رويه وعيه

أ.د. أعلى السيد الثخيبى مهره

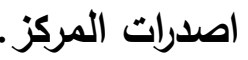


أ.د/ زينب محمد حسن خليفة

مقدمة العدد

كشاف المجلة من العدد الأول إلى العدد الرابع والثلاثون دراسات ويحوث

أ. أمل حسان السيد حسن معايير تصميم الإنفوجرافيك التعليمى التوجهات المعاصرة للتمية المهنية القائمة على المدرسة، وإمكانية الإفادة منها د. أميرة خيري على أحمد الند

بمؤسسات رياض الأطفال فى مصر فاعلية تصميم قصة رقمية قائمة على مدخل الثكل الخطى "المنتظم" فى تتمية التحصيل لاى التلاميذ ذوى صعوبات تعلم الرياضيات بالمرحلة الابتدائيه

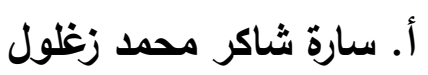

فاعلية عناصر التعلم عبر الويب في تتمية مهارات تصميم المقررات الالكترونية لاى

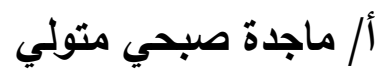
طلاب تكنولوجيا التعليم معوقات تطبيق الإشراف التربوي الإلكتروني في المرحلة الإعدادية بمحافظة سوهاج من وجهة نظر المشرفين التربوبين: دراسة ميدانية

د/ عبد العاطى حلقان أحمد عبد العزيز

المهارات العملية اللازمة لتلاميذ المرحلة الإعدادية في مادة التربية الزراعية

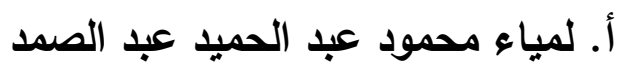

بعض قضايا التعليم بمجموعة دول غرب أفريقيا " دول الأكواس " فى مجلة قراءات أفريقية" دراسة تحليلية " أ.م.د. محمد أحمد محمد إسماعيل رؤية مقترحة للتتمية المهنية لمعلمات رياض الأطفال فى ضوء بعض الاتجاهات

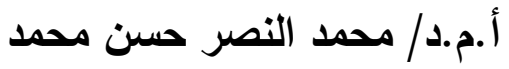
المعاصرة الثبهة المثارة حول أرث المرأة المسلمة والرد عليها ـــ مريم بنت أحمد الخالد 
أثز برنامج تعليمي باستخدام السبورة الذكية على تتمية التفكير الابتكاري للتناميذالصم أ. ولاء كمال حسن مرسي الابخي

ملخصات رسائل علمية ملخص رسالة دكتوراة

منهج مفترح فى الكيمياء لطلاب المرحلة الثانوية قائم على التكامل بين الاحتياجات الحياتية ومتطلبات العمل لتتمية مهارة اتخاذ القرار والميول المهنية أ. عصام محد سبي أحمد

ملخص رسالة ماجستير فعالية المدخل الجمالى فى تدريس البيولوجى لتتمية بعض المفاهيم العلمية الكبرى، وآراء الطلاب والمعلمين بالمرحلة الثانوية نحو استخدامه أ. أمانسى محمد عبد الحميد أبوزيـــ أهـ

ملف العدد

مركز تظوير التعليم الجامعى مستحدثات التكنولوجيا فى تطوير التعليم اصدرات المركز..........................

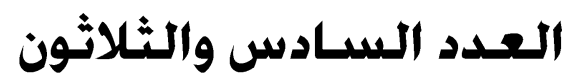
أ.د/ زينب محمد حسن خليفة مقدمة العدد كثاف المجلة من العدد الأول إلى العدد الخامس والثثلاثون دراسات ويحوث اليوسي ماس وتتمية الاتجاه نحو الرياضيات وتتمية التحصيل لدى طلاب المرحلة أ.م.د. أحمد بن سالم بن سلمان السميري الابتدائية التعليم والتنافسية في نايلاند وإمكانية الإفادة منها في تطوير نظام التعليم قبل د. أحمد محمد نبوي حسب النبي الجامعي في مصر 
مشروعية الدليل الالكتروني الصادر عن التفنش الجنائي "دراسة مقارنة" د/ فهز دخين العدواني

تصور مقترح لتطوير التعليم الأساسي في مصر على ضوء التوجهات العالمية

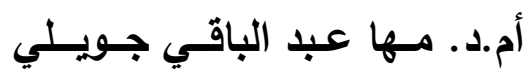

فاعلية تتوع الأنشطة ببرامج الكمبيوتر التعليمية في تتمية التحصيل المعرفي والإدراك

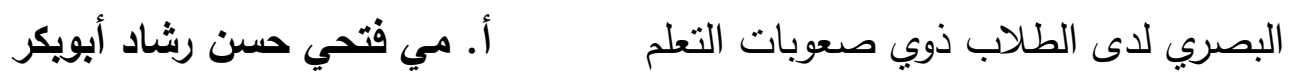
تصور مقترح لتطوير نظام الدراسة والامتحان بشهادة الثانوية العامة في مصر على ضوء سياسات القبول بالتعليم العالي ــناء إبراهيم إبراهيم سليمان أثر بعض متغيرات عرض المثيرات البصرية في برامج الكمبيوتز التعليمية على تتمية مهارات الاتصال الالكتروني لاى ضعاف السمع د. هناء عبدالعال محمد القسم الثالث: ملخصات رسائل علمية ملخص رسالة ماجستير فاعلية برنامج مقترح لإكساب طلاب تكنولوجيا التعليم مهارات إنتاج الصور المولدة أ. وليد محمد عبد الحميذ دسوقى مهئ بالحاسوب

ملخص رسالة دكتوراة فاعلية برنامج تدريبي مدمج قائم على الاحتياجات المهنية لتتمية الأداء التدريسي

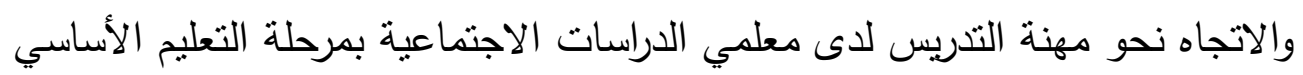
أ.علي محمد أبوالمعاطي إبراهيم

$$
\text { "بحث إجرائي" }
$$

القسم الرابع: ملف العدد

تقنية الواقع المعزز Augmented Reality وتطبيقاتها في عمليتى التعليم والتعلم أ.م. د / هناء رذق محمد

اصدرات المركز............... 
أ.د/ زينب محمد حسن خليفة

مقدمة العدد

كشاف المجلة من العدد الأول إلى العدد السادس والثثلاثون

دراسات ويحوث

أدوار مؤسسات المجتمع المدنى التطوعية فى تحقيق العدالة الاجتماعية فى الولايات المتحدة الأمريكية والسويد وإمكانية الإفادة من خبراتها فى مصر

د. أحمد محمد نبوي حسب النبي

المضامين التربوية الاجتماعية لصلاح الأمة المستتبة من كتاب الآداب الثرعية

$$
\text { والمنح المرعية لابن مفلح المقدسى وتطبيقاتها فى الحياة اليومية }
$$

د. رجاء بنت سيا على بن صالح المحضار

فاعلية الرسوم الكاريكاتورية على التحصيل الدراسى والتقكير الإبداعى فى مقرر العلوم

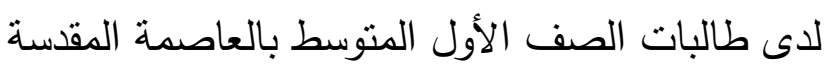
أ.رشا بنت احمد هاشم فلبمان

فلسفة دمج ذوى الاحتياجات الخاصة بمدارس العاديين ومشكلاته كما يراها المعلمون د. هويدا محمود الإتربى

" دراسة حالة على محافظة الغربية" القسم الثالث: ملخصات رسائل علمية ملخص رسالة ماجستير أثز استخدام التعليم المدمج فى علاج صعوبات تعلم القواعد النحوية لدى تلاميذ أ. أحمد محمد حسين مصطفى

المرحلة الابتدائية 
أثز اختلاف نظام العرض "أحادى الرؤية-مجسم الرؤية" لفيلم تعليمى ثلاثي الأبعاد فى تتمية مهارات التفكير البصرى وحل المشكلات لدى طلاب تكنولوجيا التعليم أ.وليد محمد عبدالحميد دسوقى لكوليا

القسم الرابع: ملف العدد

أ.د. عزة محمد عبدالسميع

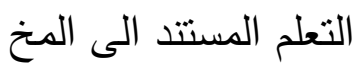
اصدرات المركز..............

\section{العدد السسابع والثلاثون هكيرر}

أ.د/ زينب محمد حسن خليفة

مقدمة العدد كشاف المجلة من العدد الأول إلى العدد السابع والثنلاثون دراسات ويحوث فاعلية وحدة مقترحة قائمة على استراتيجية العصف الذهني فى تتمية مهارات القراءة الإبداعية لدى طلاب الصف التاسع بدولة الإمارات العربية المتحدة د.أحمد عبد الظاهر عزت أه

المهارات اللازمة لتصميم وإنشاء قواعد البيانات لدى طلاب شعبة تكنولوجيا التعليم

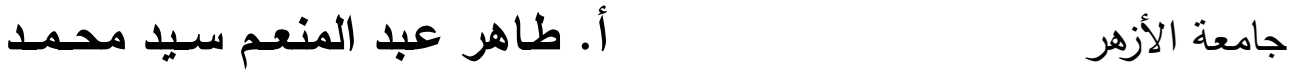
التربية الريادية ومتطلباتها من التعليم الجامعي في ضوء اقتصاد المعرفة من وجهة نظر أعضاء هيئة التذريس بجامعة سوهاج أ.عماد عبد اللطيف محمود تطوير الأداء البحثي بالجامعات المصرية في ضوء قياس كفاءته النسبية باستخدام مدخل التحليل النطويقي للبيانات (مع التطبيق على جامعة بنها)

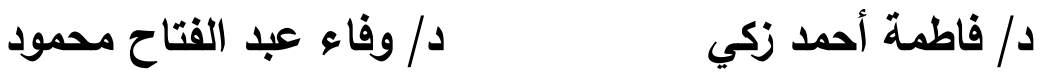


فاعلية الألعاب التعليمية الالكترونية في تتمية التحصيل الدراسي وبقاء أثز التعلم في الرياضيات لدى طالبات الصف الثالث الابتدائي بمنطقة مكة المكرمة أ.مشاعل محمد عبدالله السويلم

تطوير الأداء الإداري بالجامعات السعودية بالاستفادة من أبرز نماذج الأنظمة الناجحة لحوكمة الجامعات على المستوى العالمي د/هالة فوزي محمد عيد روئية مقترحة لإنشاء حاضنات للمعرفة التربوية بالجامعات المصربة د. هيام عبد الرحيم أحمد على

اصدرات المركز............... العدد الثناهن والثناثون اصدزن

أ.د// زينب محمد حسن خليفة مقدمة العدد كشاف المجلة من العدد الأول إلى العدد السابع والثلاثون مكرر دراسات ويحوث

تقويم مدى تمكن تلاميذ الصفوف الثناثة الأولى من المرحلة الابتدائية بدولة الإمارات العربية المتحدة من المستويات المعيارية لمهارتي القراءة والكتابة د. أحمد عبد الظاهر عزت ابه

مدخل التنبؤ بالقوي العاملة في هولندا وألمانيا وفنلندا وانجلترا والولايات المتحدة الأمريكية وإمكانية الإفادة منه في مصر د. أحمد محمد نبوي حسب التبي أفضل الممارسات فى التدريب والتتمية المهنية (اتجاهات ونماذج عالمية وإقليمية أ. دعاء السيد عبد المطلب مسعود ووطنية)

" تصور مقترح للتنمية المهنية لمعلمي التعليم الثانوي الصناعي في ضوء الاتجاهات

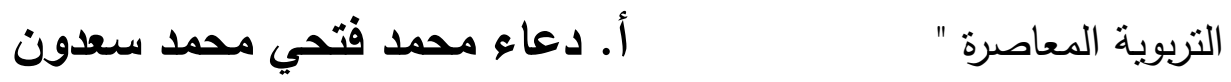


المضامين التربوية الاجتماعية لصلاح الأمة المستتبطة من كتاب الآداب الثرعية والمنح المرعية لابن مفلح المقسي وتطبيقاتها في الحياة اليومية الية الهية

د. رجاء بنت سيا علي بن صالح المحضار

تصور مقترح لتطوير المسؤولية المجتمعية بالجامعات السعودية في ضوء الاتجاهات د. سعد مبارك الرمثي العالمية الحديثة واقع ممارسات التريس البنائي لاى معلمات الرياضيات في المرحلة الابتدائية بمدينة أ.نادية بنت طلق بن صالح العتيبي الرياض.

القسم الثالث : ملخصات رسائل علمية ملخص رسالة ماجستير بعنوان علاقة مستوى الكتابة وأسلوبها باستراتيجيات الكتابة لاى متعلمي اللغة الألمانية كلغة أجنبية " رياض سليمان السيد طه ملخص رسالة دكتوراة " فعالية برنامج قائم على استخدام بعض المستحدثات التكنولوجية في تتمية أبعاد التتور العلمي لطلاب الثعب الأدبية بكلية التربية " د.حنان حامد سيد إسماعيل

القسم الرابع : ملف العدد Learning Analytics تكنولوجيا تحليلات التعليم أ.د. زينب محمد حسن خليفة

$$
\text { اصدارات المركز ..... }
$$

